\title{
Secondary rhinoplasty: reconstitution of the allar cartillages by a rhinoplasty with an external incision
}

\author{
Otorhinolaryngology Discipline, Hospital das Clínicas, Faculdade de Medicina da \\ Universidade de São Paulo - São Paulo, Brazil
}

\begin{abstract}
Presentation of 62 cases of secondary nasal deformities treated by external incision. Several types of endonasal deformities were observed, properly classified and repaired. When excessive ressection was observed, local cartillage graft, septonasal or conchal types were employed.
\end{abstract}

UNITERMS: Nose. Secondary rhinoplasty.

\section{INTRODUCTION}

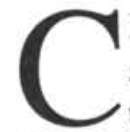
lassic endonasal rhinoplasty does not enable a symmetric ressection of the allar cartillages. Due to this, presence of secondary endonasal deformities is very frequent.

Opening utilization, with a whole exposition of the cartillages, enabled an exact evaluation of deformities and, as a result, a more precise restoration.

In all of the cases, wrong removals were observed, resulting in the most different types of deformity, ranging from since a small asymmetria until a complete collapse, with total ressection of the cartillages.

After Rethi (4), Sercer (5), Padovan (3) and, most recently, Goodman (1 and 2), Sheen (6), divulgated rhinoplasty through nose openings, we have observed that treatment of the secondary deformities as well as some

\section{Address for correspondence: Jorge Ishida \\ Rua Padre Pereira de Andrade, 545 \\ Ilha do Sul - Ed. IIha Bela, 123/124 \\ São Paulo - SP - Brasil - CEP 05480-000}

congenital ones, have been extremely improved by this procedure. Incision initially used was the one described by Rethi (4) and, afterwards, we have adopted the one proposed by Goodman ( 1 and 2 ), bearing the medium portion of the columella and in a broken line. This procedure resulted, in most of the cases, in a quite invisible scar 3 months ago.

In spite of requiring a longer surgery time, the wide exposition of the anatomic elements, a more symmetrical reparation of the elements is possible.

\section{SURGICAL TECHNIQUE}

Incision begins in the marginal portion of both of the wings and is extended till the columella.

Endonasal cutaneous dettachment starts on the point subcutaneous cellular tissue is more flabby continuing slowly in direction to the columella, where there is a higher adherence of the skin to the cartillage. In this point of surgery, incisions join each other at the medium part of the columella, in the form of a smal inverted " $\mathrm{v}$ ".

This sequence results in a faster dettachment of skin, avoiding trauma and, sometimes, skin scrubbing at the 
columella point. Also, it is very important that, in some cases, even being scheduled an open rhinoplasty, deformity can be treated only by a marginal incision, being not necessary free columella in its entirety.

\section{DIAGNOSIS AND TREATMENT}

Sixty-two cases of endonasal deformities were treated. Deformities can be classified as follows:

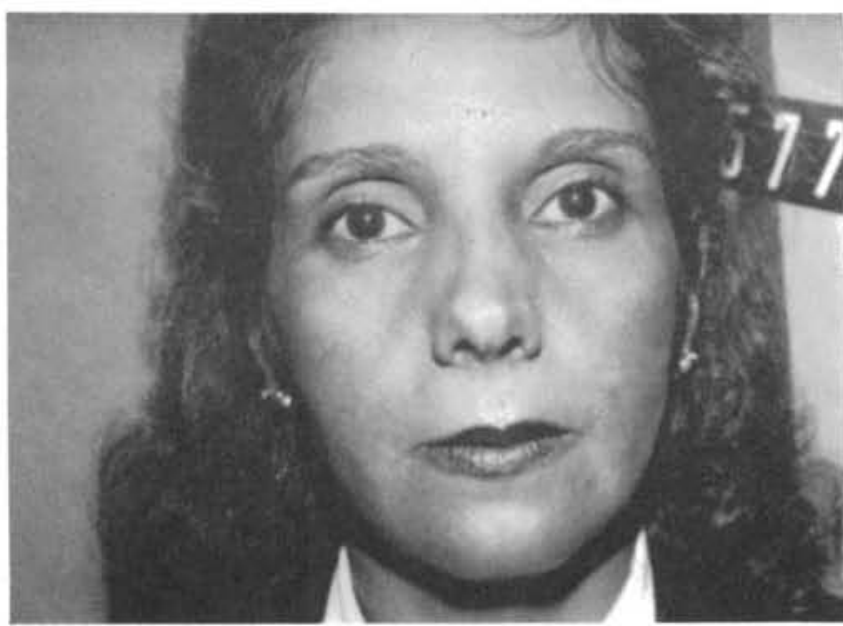

Figure 1A - Preoperative semblanceof the patient with endonasal asymmetry, saddle nose

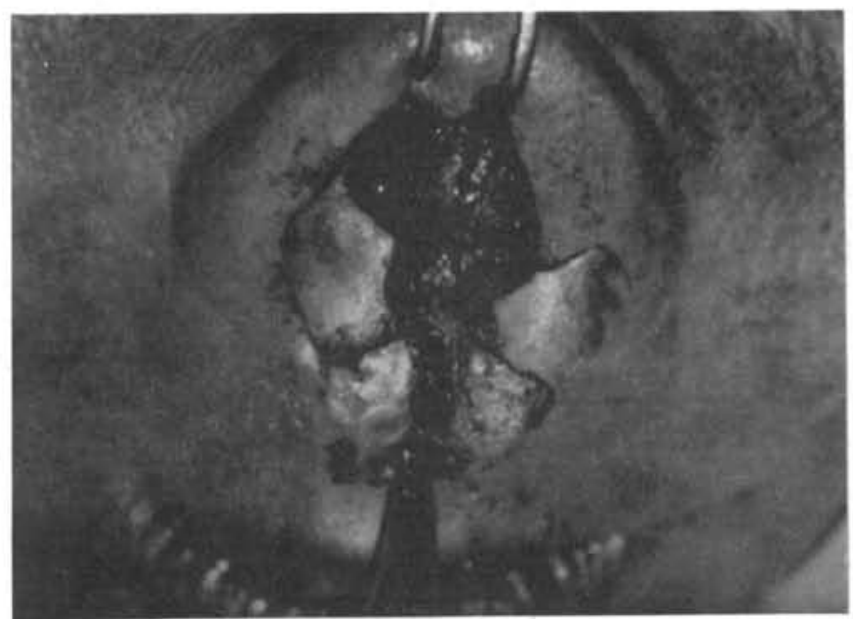

Figure $1 \mathrm{C}$ - Aspect of the alar cartillage restoration with alar cartillage left overs
1. Excessive ressection

2. Asymmetric ressection

3. Insufficient ressection

4. Total ressection

In $100 \%$ of the cases asymmetric ressection was observed, even in the total ones, due to differences in the remaining stump.

Treatments were classified in two groups:

1. Insuficient and asymmetric cases: we tried to free allar cartillages in its entirety, since the medial cross till extremety; approaching both cartillages, side by side, a completely symmetrical ressection is possible to be done.

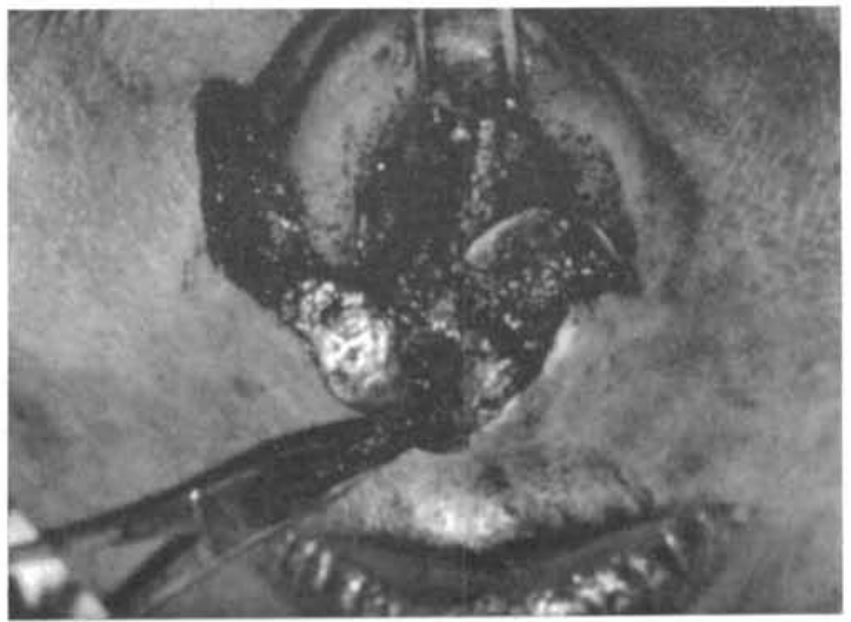

Figure 1B - Aspect after endonasal exposition, high asymmetry of the alar cartillages, right alar cartillage seccioned right above domus

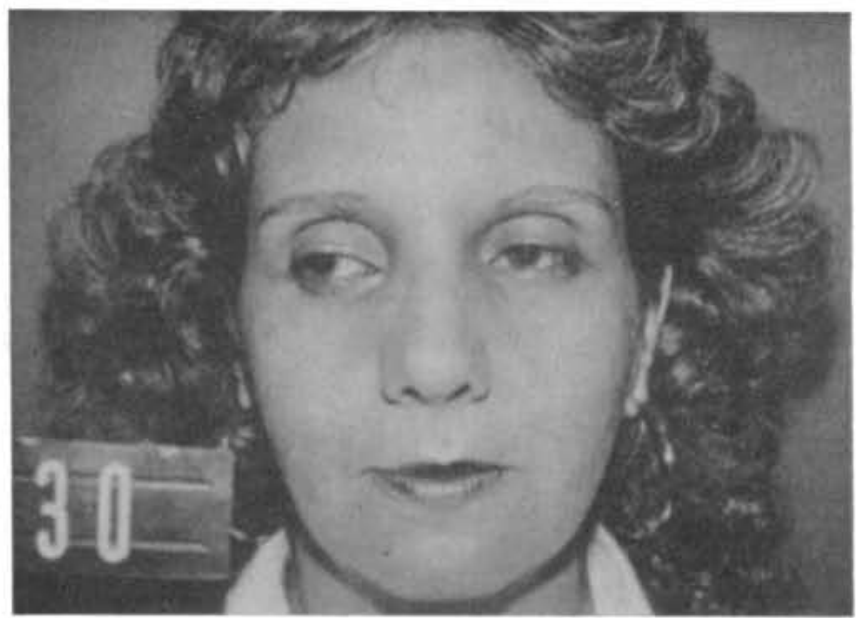

Figure 1D - Final aspect of the patient, 6 months after surgery 


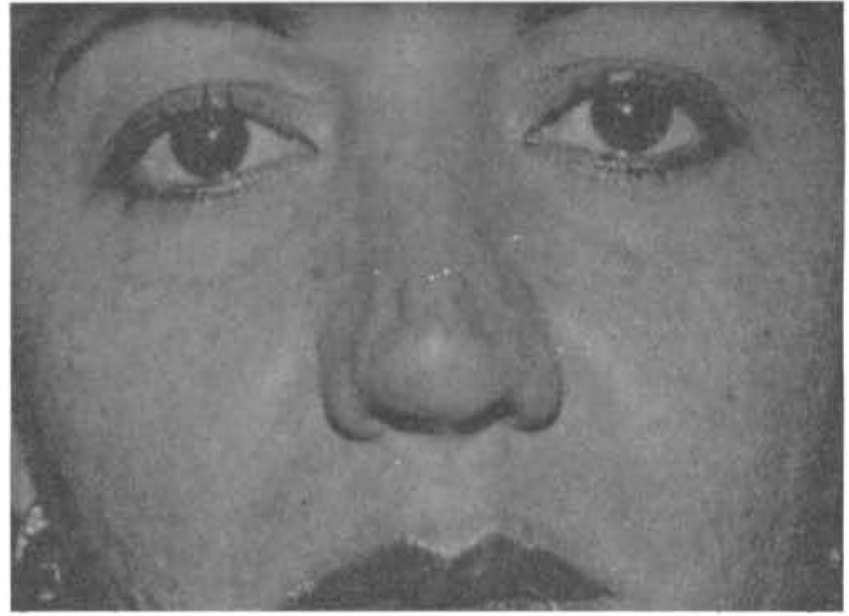

Figure 2A - Preoperative aspect, with pinced endonasal

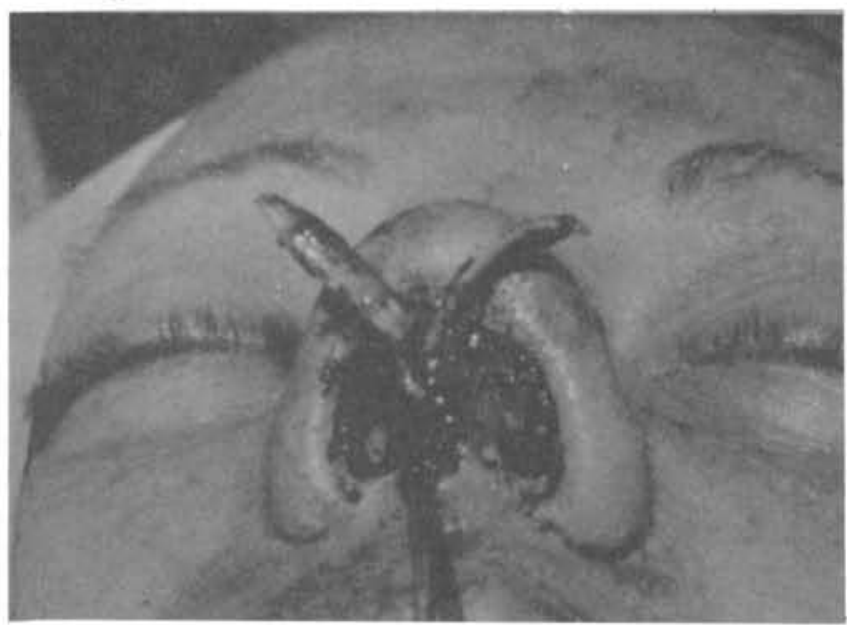

Figure 2C - Aspect of the graft sutures in the medial stump of the alar cartillages

2. In the excessive and total ressection cases, we reccur on to grafts of the remaining allar cartillages, septal cartillages or conchal ones.

We frequently obtain leftover fragments from the more lateral portion, that are dissected and sutured to the portion where an excessive ressection has been done. Suture is done with monofilar nylon thread 6.0 (Fig.1 $\mathrm{A}, \mathrm{B}, \mathrm{C}$ and D).

When septal cartillage is chosen,we use fragments of approximately $2.5 \times 1 \mathrm{~cm}$, carved to reproduce the allar cartillage (Fig, 3 A,B,C,D,E,F,G). Carefully, cartillage is divided in its whole espessure. We observe that the 2 sheets obtained present a convexity, rigorously in the same format as the allar cartillages (Fig.3 A and B).

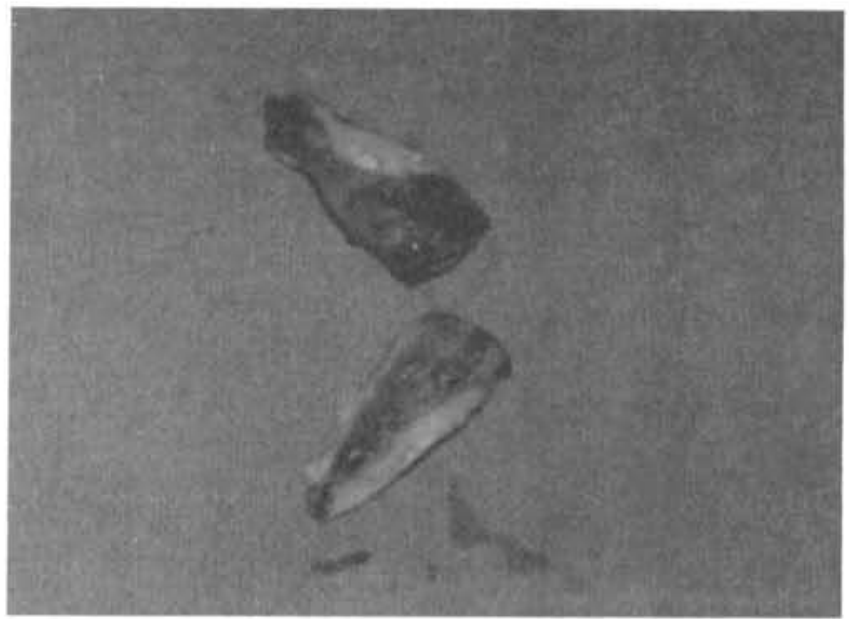

Figure 2B - Conchal cartillages carved, reproducing alar cartillage form

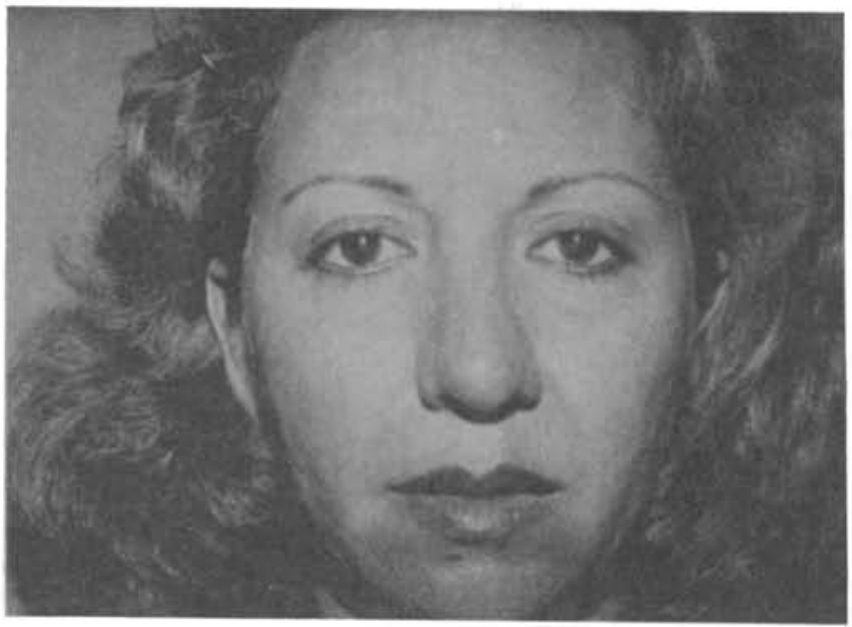

Figure 2D - Final aspect of the endonasal, 6 months after surgery

These cartillage sheets are sutured on the remaining cartillage stump (Fig.3 C,D,F).

In order to get symmetric and, mainly, the same resistance, stumps must be withered to the same level, so as the suture graft.This procedure avoids distortion and uneveness of the future endonasal.

Conchal graft is obtained through a retroauricular incision and wide dettachment of the conchal cartillage. Two convex and symmetric portions are chosen and properly withered. Conchal cartillages, being very thick, need to be carved, mainly in the edges, where they are slender (Fig.2 A,B,C,D).

In some cases, in order to avoid very large ends, some incisions may be done to decrease the spring resistence. 


\section{RESULTS}

Endonose was restorated in all of the surgeries performed. Small asymmetry was observed in 2 cases. In one of them, where a simultaneous dorsal grafting was performed, an infection occurred, but was satisfactorily solved by antibioticotherapy.

\section{DISCUSSION}

Rhinoplasty with external incision introduced new aspects in the treatment of secondary nose deformations, mainly in what refers to the endonose structural

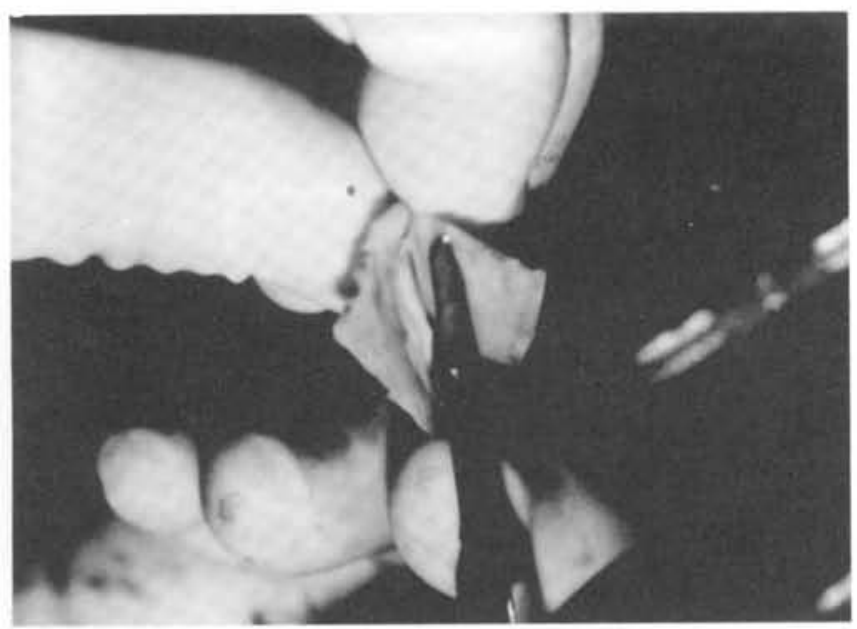

Figure 3A - Fragment of septal cartillage being biparted to obtain cartillage graft for the wing of the nose. The two cartillage sheets show side curve tendency, becoming convexed

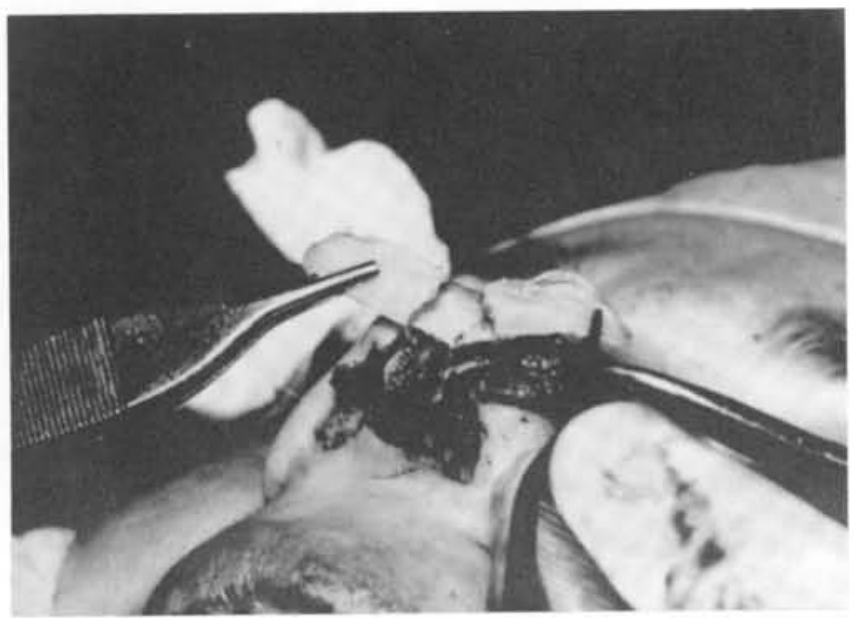

Figure $3 \mathrm{C}$-Aspect of endonasal placing, being prepared for suture components. Complete view of elements "in situ" enables precise anatomic diagnosis and the large exposition of the surgical area enables surgical procedings, difficult to be performed by the endonasal usual ways. Assessment of losses and cartillage graft on the wings can be done symmetrically.

The three methods applied for the endonasal restoration showed to be very efficient. In small failures, use of small fragments obtained from leftovers of the allar cartillage itself, in terms of results, was the easiest method and the best one, due to the structure and characteristics of this cartillage.

Conchal cartillage, due to higher thickness and less flexibility, even modulable, resulted in a slightly bulbous and firm endonasal.

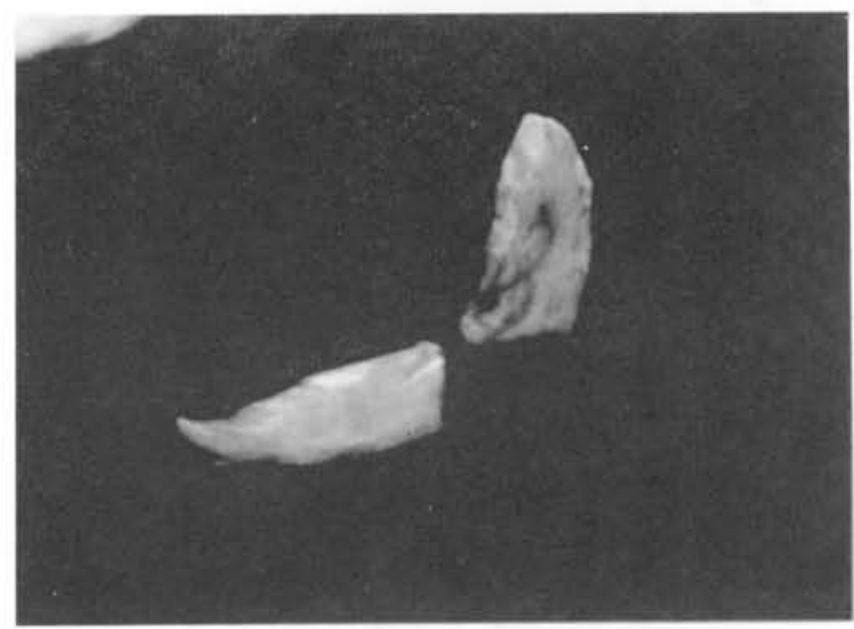

Figure 3B - Septal cartillage divided in the middle, showing the convex form they acquire

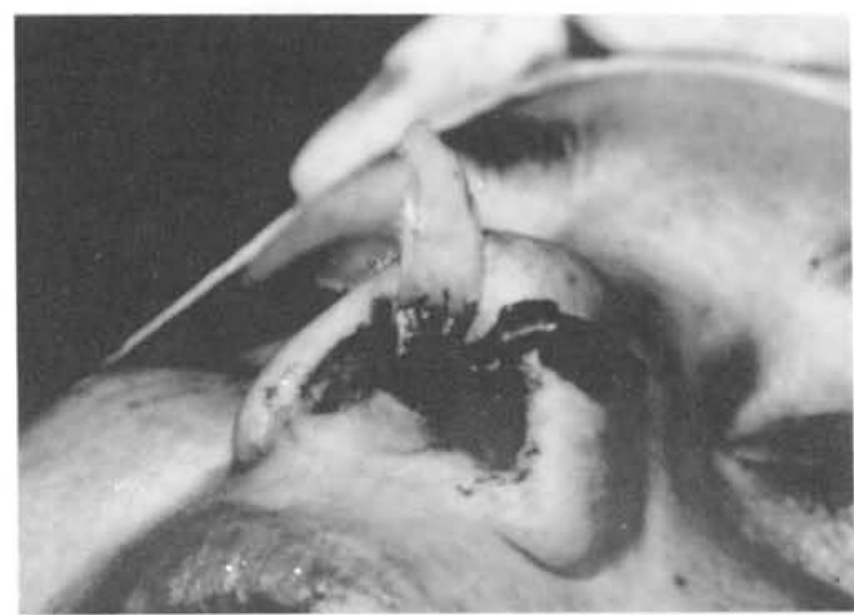

Figure 3D - Septal cartillage sutured to medial cross of the alar cartillage 


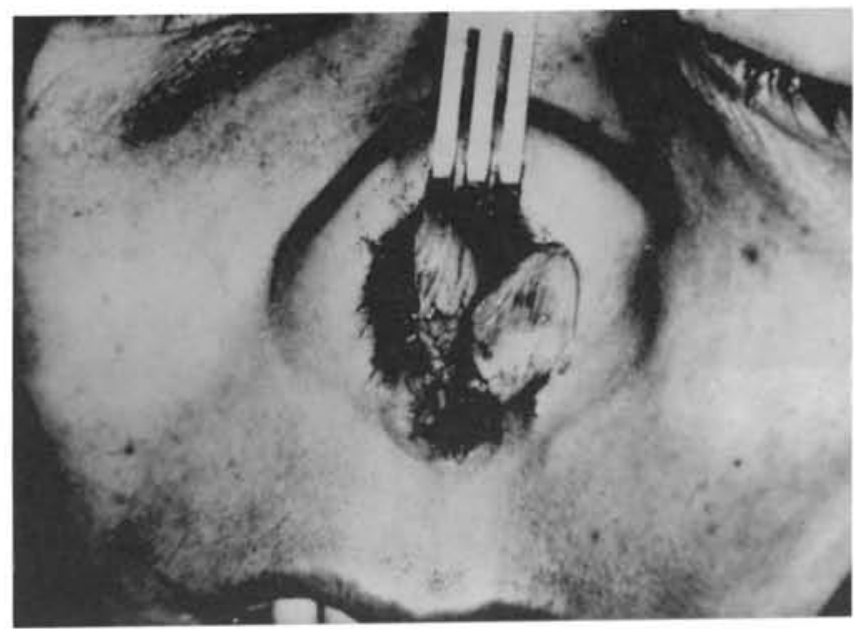

Figure 3E - Aspect after the graft suture on the cartillageous stump

\section{RESUMO}

Objetivo: Apresentação de 62 casos de deformidades nasais secundárias tratados por incisão externa. Resultados e Conclusão: Foram verificadas diversas formas de deformidades de ponta, que foram classificadas e reparadas. Quando foi constatada ressecção excessiva utilizamos enxerto de cartilagem local, enxerto de septo ou cartilagem conchal.

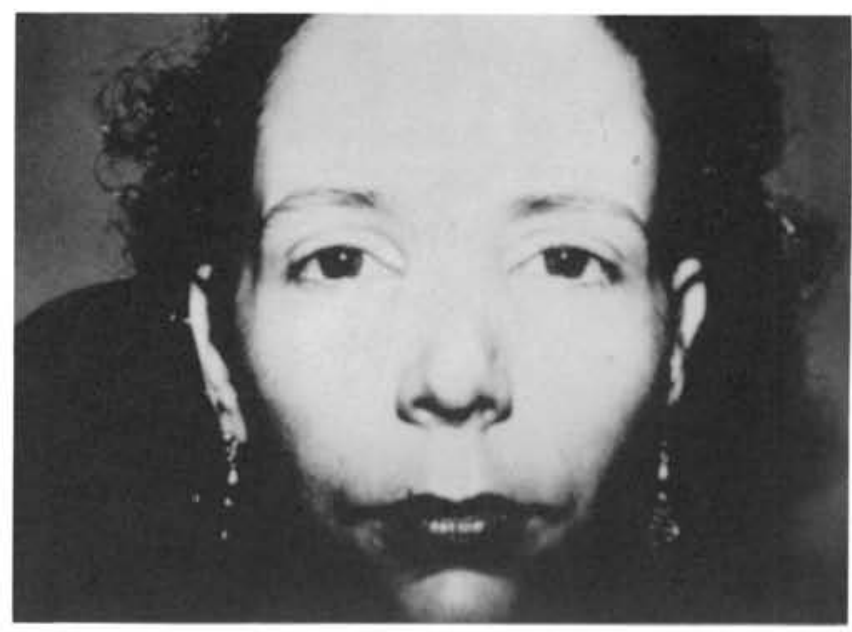

Figure 3F - Preoperative aspect of patient showing the endonasal pincement. Cartillage missing on the lateral area

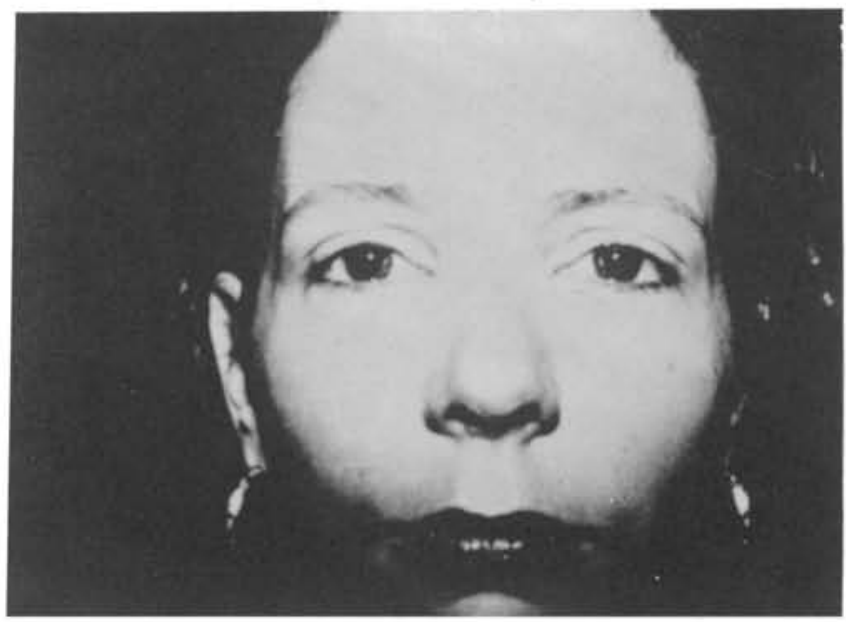

Figure $3 G$ - Postoperative aspect, after restoration with septal cartillage grafting

\section{REFERENCES}

1. GOODMAN, W.S. - External approach to rhinoplasty. Can J Otolaryngol 2:207,1973.

2. GOODMAN, W.S. - Recent advances in external rhinoplasty. J Otolaryngol 10:433., 1981.
3. PADOVAN, I. - External approach to rhinoplasty (decortication) Ann Otol Rhinol Laryngol 3-4: 354, 1966.

4. RETHI, A. - Operation to shorten an excessively long nose. Rev Chir Plast 2:85, 1934.

5. SERCER, A.: - Dekortication der Nase. Chir Maxillofac Plast 1:149, 1958.

6. SHEEN, J. - Aesthetic Rhinoplasty. Mosby, 1987. 